\title{
Numerical simulation of extreme wave runup during storm events in Tramandaí beach, Rio Grande do Sul, Brazil
}

\author{
Pedro Veras Guimarães ${ }^{\mathrm{a}, \mathrm{c}, *}$, Leandro Farina $^{\mathrm{b}, \mathrm{c}}$, Elirio Toldo Jr. ${ }^{\mathrm{a}}$, Gabriel Diaz-Hernandez ${ }^{\mathrm{d}}$, Elena \\ Akhmatskaya ${ }^{\mathrm{c}, \mathrm{e}}$ \\ ${ }^{a}$ CECO - Centro de Estudos de Geologia Costeira e Oceânica, Instituto de Geociências, Universidade Federal do Rio Grande do Sul, \\ Campus do Vale Av. Bento Gonçalves 9500, Porto Alegre, RS, Brazil \\ ${ }^{b}$ Instituto de Matemática and CECO - Centro de Estudos de Geologia Costeira e Oceânica, Universidade Federal do Rio Grande do \\ Sul, Campus do Vale Av. Bento Gonçalves 9500, Porto Alegre, RS, Brazil \\ ${ }^{c}$ BCAM - Basque Center for Applied Mathematics, Alameda de Mazarredo 14, 48009 Bilbao, Bizkaia, Spain \\ dInstituto de Hidráulica Ambiental "IH Cantabria", C/ Isabel Torres 15, Parque CientíÂfico y Tecnológico de Cantabria 39011 \\ Santander, Spain \\ ${ }^{e}$ IKERBASQUE, Basque Foundation for Science, E-48013 Bilbao, Spain
}

\begin{abstract}
We present a high resolution analysis of the interaction of irregular waves with natural and urban structures leading to extreme wave runup. Horizontal runup data, instantaneous flooding maps, and wave propagation beyond the coastline are numerically predicted. The novel methodology combining the Wave Watch III, SWAN and SWASH models to achieve accurate and computationally feasible simulation of waves at different time and spatial scales, from the formation process at deep water up to the total energy dissipation in the swash zone, is proposed. An access to the LIDAR database has provided a high resolution $(15 \mathrm{~cm}-25 \mathrm{~cm})$ of the subaerial surface which is essential for accurate representation of the hydrodynamic interactions with the beach profile. The suggested approach has been applied for evaluation of wave runup related to six storm events in Tramandaí Beach in Southern Brazil. This allowed for an identification of critical vulnerable overwashing areas as well as, critical information on flooding zones. The results are in an agreement with the runup measurements performed in January 2014. The numerical methodology employed in this work have been also compared with the survey and conventional empirical models data. It was discovered that the empirical models lead to the systematic overestimation of the runup results.
\end{abstract}

\section{(C) 2011 Published by Elsevier Ltd.}

Keywords: Small scale ocean waves process, Waves runup, Storm events, Coastal hazards, Coastal flooding

\footnotetext{
${ }^{*}$ Corresponding author

Email addresses: pvgu ima@gmail.com (Pedro Veras Guimarães), farina@mat.ufrgs.br (Leandro Farina), toldo@ufrgs .br (Elirio Toldo Jr.), gabriel.diaz@unican.es (Gabriel Diaz-Hernandez), akhmat skaya@bcamath.org (Elena Akhmatskaya)
} 


\section{Introduction}

Storms represent one of the most significant natural threats to coastal communities, leading to lives lost and property damage (Almeida et al., 2012). Storm events can cause coastal erosion, coastal flooding, damage to infrastructure and other undesirable effects, thus creating the need for management tools, such as vulnerability maps, predictive techniques or warning systems, that can help to prevent these negative consequences.

In general terms, the impact of storms on the coast is determined by the cumulative effect of waves, winds, currents, tides, topographies and even the anthropic modifications in the local field. All these processes dynamically interact at different time scales. Often, storms produce increases in water levels. Further, spring tides can induce dune ridges overtopping and overwashing, causing other types of coastal damage, including destruction of coastal properties and engineering structures. Waves play an important role in these processes by carrying and dissipating large quantities of energy to the beach. Their destructive power presents major challenges for coastal management, and knowledge of their characteristics and associated consequences is therefore of paramount importance.

Historically, many studies have been carried out in order to estimate a maximum waves runup and evaluate a storm waves impact. These include the work by Iribarren and Nogales, 1949 on a wave runup in laboratory experiments using regular waves on impermeable slopes. Stockdon et al., 2006 calculated the $2 \%$ exceedance wave runup and compared it with the field measurements on beaches in the USA and the Netherlands. Callaghan et al., 2009 presented the practical applications in coastal planning and risk assessment of wave runup in storm events. In addition, Nielsen, 2009 showed the physical factors (e.g. a beach topography) interfering in the variability of wave runups. While those authors focus on empirical methods to approximate the wave runup, another group of researchers work towards improvement of near-shore numerical models. A numerical approach has an advantage of dynamically computing the sea state, using known boundary conditions. Its limitation lies in the possible large computational demands.

Modeling of wind generated waves is often done by using spectral wave models of third generation. The models of this type, such as WAM 1988, Komen et al., 1994) and WaveWatch III (Tolman, 1991, 1997 e 2009) have been proved to be adequate for description of waves in deep to intermediate waters. On the other hand, the SWAN model (Booij et al., 1999) is used preferably in coastal waters.

Recently, to improve description of waves in very shallow waters under extreme conditions caused by storms, Dietrich et al., 2011 have suggested a coupling of SWAN with the hydrodynamic model ADCIRC. This provided a tool for modeling of waves, tides and storm surges caused by hurricanes ( Fleming et al., 
2013).

The state of the art non-linear phase-resolving wave numerical models are usually based on either a Boussinesq-type formulation or on a non-hydrostatic approach. The Boussinesq models are well established (e.g. Madsen et al., 1991; Nwogu, 1994; Wei et al., 1995) and have been very successful in applications for near-shore regions. However, numerical implementation of large models required for high accuracy is rather complicated. The non-hydrostatic approach is more recent (e.g. Stelling and Zijlema, 2003, Yamazaki et al., 2009. Ma et al., 2012) and uses an implementation of the basic 3D mass and momentum balance equations for a water body with a free surface. In this case, the Euler equations can be supplemented with the second-order shear-stress terms when required, resulting in the Navier-Stokes equations, with a singlevalued function of the horizontal plane (as used in the SWASH model, Zijlema et al., 2011).

\subsection{Field description}

In Brazil, storm events are particularly important in the southern area where they act strongly, sometimes causing surges, overtopping, overwashing and can potentially lead to public and private damages.

The Rio Grande do Sul coast is especially sensitive to a waves impact because of its unconsolidated sedimentary sandy barrier known as one of the longest sandy barriers in the world (615 km long) with only two permanent discontinuities, namely in the Tramandaí and the Patos Lagoon inlets (Dillenburg et al., 2004). Rio Grande city, close to the Patos Lagoon mouth, has a national strategic port facility whereas Tramandaí city receives much of the oil by means of the local offshore buoy. Tramandaí and Imbé, another city in the north, are characterized by a high urban concentration near beaches. Guimarães et al., 2014 found that the northern region of the Patos Lagoon inlet has a shallow water waves energy concentration during extreme waves events and the region between Imbé and Tramandaí is at potential risk from storms at the Rio Grande do Sul state.

Imbé and Tramandaí cities are located in the northern part of the Rio Grande do Sul littoral divided by the Tramandaí River tidal inlet (Fig. 1). Imbé sits in the north of this inlet, with the economy based on tourism and construction. This is the high urbanization area in the north of the Rio Grande do Sul littoral $(99,95 \%$, according to IBGE, 2010), but only $20 \%$ of residences are permanently occupied and the other $80 \%$ are second residences for the summer season. Tramandaí is older than Imbé, with the higher population and more permanent residences. Between 1959 and 1961, the Tramandaí's inlet has been fixed by currents guides whereas the outflow mouth position has been changed and dislocated to the south. Figure 1 shows the domain described above and identifies the main beach morphologies presented there. 

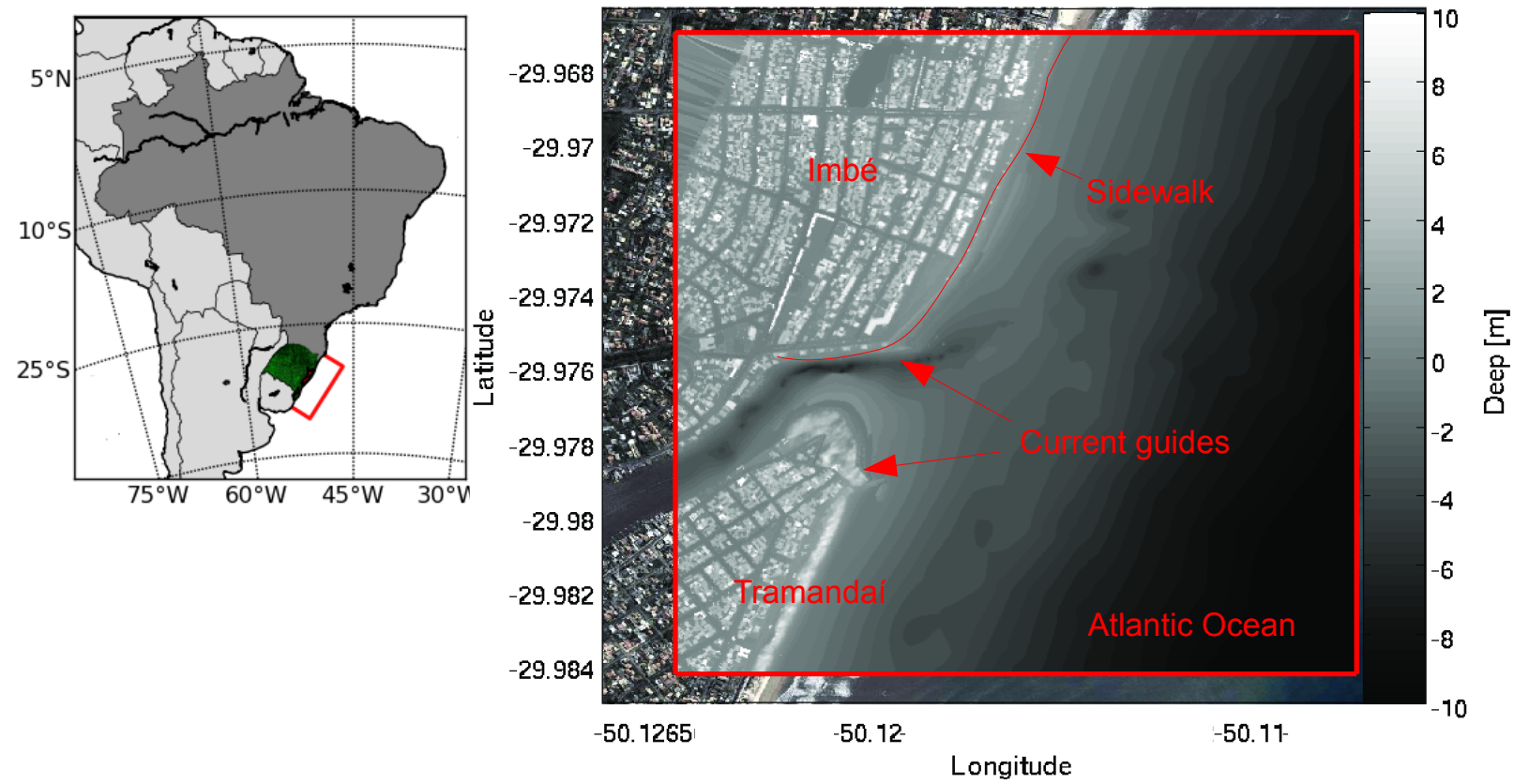

Figure 1. The study field representation. Red lines present the grid boundaries for the SWAN model (left) and for the SWASH model (right). The right image shows the computational bathymetry over a google earth image (gray scale). The positions of two current guides and the Imbé sidewalk are indicated by red arrows (left).

The Tramandaí beach has been described by Toldo et al., (1993) as a wide sandy dissipative beach with a longitudinal bar through the structure. The foreshore of this beach is wide and flat with sand is the predominate deposits (Toldo et al., 2006). The astronomical tide is semi-diurnal with a mean amplitude of $0.25 \mathrm{~m}$. The meteorological tide may reach an amplitude of $1.20 \mathrm{~m}$ (Toldo et al., 2006). The closure depth is estimated as of $7.5 \mathrm{~m}$, calculated from two sets of the wave data collected in years 1963 and 1996 on the Stateś northern coast (Toldo et al., 2006). The beach is subject to swells generated in the Southern Atlantic Ocean and local waves produced by strong local winds in spring and summer, blowing from the NE. Except for the periods when cold fronts arrive from the S and SE, the sea surface is characterized by waves of medium to high energy with the significant height of $1.5 \mathrm{~m}$ and the period between $7 \mathrm{~s}$ and $9 \mathrm{~s}$. However, during some storm surge events, a waves height in shallow waters can exceed $2.5 \mathrm{~m}$ reach with 14 s of a peak period, as described by Guimarães et al., 2014.

The inner shelf circulation and the sea surface height are mainly driven by wind at synoptic timescales (Lima et al. 1996, Stringari and Marques 2014). This region has a high seasonal and interannual wind 
variability (Piola et al., 2005. Braga and Krusche, 2000). The NE winds are associated with a high pressure center generated by the semi-stationary anticyclone in the South Atlantic. Dominant in the summer, the anticyclone forces a displacement of water constituents to S-SE (Möller et al., 2008). In the winter, the SW wind generates a water displacement to the NW (Möller et al., 2008). This seasonal water displacement is responsible for a water level set-down in the coast during the summer and for a set-up during the winter.

According to Machado et al. (2010), the mid-latitude cyclogenesis with low pressure centers in deep ocean and along the coast increases the intensity of mid-Atlantic storms. This causes storm surges and storm waves at Rio Grande do Sul coastal zone where the maximum values of storm surges are associated with $\mathrm{S}-\mathrm{SW}$ wind. The magnitude of the storm surges in the coast can reach the values of $1 \mathrm{~m}, 1.4 \mathrm{~m}$ and $1.9 \mathrm{~m}$, as reported by Calliari et al. (1998), Saraiva et al. (2003) and Parise et al. (2009) respectively. In addition, sea level elevations at the shore can be further amplified by the presence of shelf waves and by the piling up of water due to wave breaking processes in the surf zone (a wave set-up).

The current work intends to better understand how the local beach morphologies and urban structure respond to the extreme hydrodynamic conditions during storm events. By means of state of the art empirical models and numerical modeling of deep, intermediate and shallow waters, we expect to assess the wave runup and the flooding areas during extreme events as well as produce the reliable tools for coastal planning and management.

The outline of the paper is the following. In Section 2 we present the numerical models suggested for this study. Section 3 describes the simulated events, the validation procedure and a comparison with empirical methods. Section 4 discusses the simulations results for six storms events affected the coast of Rio Grande do Sul, Brazil in 2002-2008. The main conclusions can be found in Section 5

\section{Numerical approach}

Our approach is to use the models WaveWatchIII, SWAN and SWASH to describe the waves very near the shore, including the surfing zone. To simulate waves from the offshore zone till shore, three hindcast numerical simulations with three different nesting schemes have been run. The basic idea was to use the WaveWatchIII hindcast database for nesting in the SWAN model rather than feeding it directly into the SWASH model. The reason for that was the known ability of the SWAN model to generate accurate shallow water spectral waves conditions for SWASH. In this way, we achieve the good representation of the waves processes on global, meso and fine scales. 
Next, we describe the models features and the employed implementations, focusing more on the model SWASH, as it is less known than the WaveWatchIII and SWAN models.

\subsection{Action balance equation models}

SWAN is the third-generation wave model that computes random, short-crested wind-generated waves in coastal regions and inland waters to solve the spectral action balance equation, treated in discrete form (Booij et al., 1999).

In this study, the simulations with SWAN were performed in a non-stationary mode over a curvilinear grid on the domain defined by the vertices $\left(51.33^{\circ} \mathrm{W}, 28.90^{\circ} \mathrm{S}\right),\left(49.24^{\circ} \mathrm{W}, 28.47^{\circ} \mathrm{S}\right)$ and $\left(54.19^{\circ} \mathrm{W}, 34.23^{\circ} \mathrm{S}\right)$, $\left(46.43^{\circ} \mathrm{W}, 30.01^{\circ} \mathrm{S}\right)$. We used a time step of 5 minutes, with the waves boundary conditions and the wind input data included every 3 hours. The tide data were corrected hourly. The computational grid has a better resolution close to the coastal areas. The resolution in deep water was around $1.5 \mathrm{~km}$ whereas in the coastal areas it was chosen to be $0.5 \mathrm{~km}$. The bottom condition for these experiments were obtained from the ETOPO1 (Amante and Eakins, 2009) corrected bathymetry with nautical charts taken from DHN/CHM! Brazil Marine through the Oceanographic Modeling and Observation Network (REMO). In Figure 1 (left), the red line indicates the boundaries of the SWAN computational domain.

To input the wave boundary conditions and the winds surface we used the results from the third generation wind wave model WaveWatchIII (Tolman, 2009) with the wave hindcast database extended from 1999 to the present (see http://polar.ncep.noaa.gov/waves). The model is maintained by the wave modeling group at the National Center for Environmental Prediction (NCEP) and covers the globe from $78^{\circ}-78^{\circ} \mathrm{N}$ at a 1 degree grid resolution in latitude and a 1.25 degree resolution in longitude. The model output data include the wind speed and direction, the bulk spectral parameters, such as Significant wave height $\left(H_{s}\right)$, Peak period $\left(T_{p}\right)$ and Mean Direction at the peak period $\left(D_{p}\right)$. The temporal data resolution is available every 3 hours. The detailed description of the model and the SWAN validation results for the Rio Grande do Sul coast can be found in Guimarães et al.,2014

\subsection{Nonlinear shallow water equations model}

The SWASH model (an acronym of Simulating WAves till SHore) introduced by Zijlema et al., 2011 is a non-hydrostatic model governed by the nonlinear shallow water equations with the addition of a vertical momentum equation and non-hydrostatic pressure in horizontal momentum equations. It provides a general

\footnotetext{
1 http: //www . mar.mil.br/dhn/chm/box - cartas - nauticas/cartas .html
} 
basis for describing complex changes to rapidly varied flows. The model uses the explicit, second order finite difference method for staggered grids whereby mass and momentum are strictly conserved at a discrete level. As a consequence, this simple and efficient scheme is able to track the actual location of incipient wave breaking. The momentum conservation enables the broken waves to propagate with a correct gradual change of a form and to resemble steady bores in a final stage. The energy dissipation due to the turbulence generated by waves breaking is modeled with the Prandtl mixing length hypothesis.

In the SWASH model, the depth-averaged, non-hydrostatic, free-surface flow can be described by the nonlinear shallow water equations that, in turn, can be derived from the incompressible Navier-Stokes equations that comprise the conservation of mass and momentum and are given below:

$$
\begin{gathered}
\frac{\partial \zeta}{\partial t}+\frac{\partial h u}{\partial x}+\frac{\partial h v}{\partial y}=0 \\
\frac{\partial u}{\partial t}+u \frac{\partial u}{\partial x}+v \frac{\partial u}{\partial y}+\frac{1}{h} \int_{-d}^{\zeta} \frac{\partial q}{\partial x} d z+c_{f} \frac{u \sqrt{u^{2}+v^{2}}}{h}=\frac{1}{h}\left(\frac{\partial h \tau_{x x}}{\partial x}+\frac{\partial h \tau_{x y}}{\partial y}\right) \\
\frac{\partial v}{\partial t}+u \frac{\partial v}{\partial x}+v \frac{\partial v}{\partial y}+\frac{1}{h} \int_{-d}^{\zeta} \frac{\partial q}{\partial y} d z+c_{f} \frac{v \sqrt{u^{2}+v^{2}}}{h}=\frac{1}{h}\left(\frac{\partial h \tau_{y x}}{\partial x}+\frac{\partial h \tau_{y y}}{\partial y}\right)
\end{gathered}
$$

Here $t$ is the time, $x$ and $y$ are located at the still water level and the $z$-axis points upwards. $\zeta(x, y, t)$ is the surface elevation measured from the still water level, $d(x, y)$ is the still water depth, or the downward measured bottom level, $h=\zeta+d$ is the water depth, or total depth, $u(x, y, t)$ and $v(x, y, t)$ are the depth-averaged flow velocities in $x$ - and $y$ - directions, respectively. $q(x, y, z, t)$ is the non-hydrostatic pressure (normalized by the density), $g$ is the gravitational acceleration, $c_{f}$ is the dimensionless bottom friction coefficient, and $\tau_{x x}, \tau_{x y}, \tau_{y x}$ and $\tau_{y y}$ are the horizontal turbulent stress terms.

In the SWASH simulations, we have used a $1000 \times 1000$ rectangular grid on the domain $\left[50.1251^{\circ} \mathrm{W}, 50.1071^{\circ} \mathrm{W}\right] \times$ $\left[29.9842^{\circ} S, 29.9670^{\circ} S\right.$ ], with a grid step of $1.735 \times 1.889 m$ in $x$ and $y$ directions respectively.

In figure 1, the SWASH grid boundaries can be seen in geographic space.

The simulation length for each test case was assigned to $28 \mathrm{~min}$ and the simulation time step was set to $0.1 \mathrm{~s}$. The results were recorded every $5 \mathrm{~s}$ and the first $5 \mathrm{~min}$ were considered as a spin up. The minimum and maximum Courant numbers were kept between 0.4 and 0.8. The total depth, $d$, was measured using a side scan sonar Humminbird 987C SI Combo with a $200 \mathrm{kHz}$ sensor system. The survey was carried on May 09, 2013 under flat waves conditions and the lines were established parallely and perpendicularly to the shore line with a $200 \mathrm{~m}$ average spacing, and with a $2 \mathrm{~m}$ bathymetric data interval acquisition until approximately $4.5 \mathrm{~m}$ depth. The survey bottom level correction was conducted with a reference situated at the 
Tramandaí lagoon mouth. The mean water level condition during each simulation was imposed considering the water level at the Tramandaí inlet measured by a tide gauge at the Brazilian Superintendency of Ports and Waterways (SPH).

To complete the system of equations, a wave spectral condition was imposed at the open boundaries of the computational grid domain. We considered 45 points for wave spectra distributed along the SWASH ocean boundaries. These conditions were taken from the time-dependent energy peak of the SWAN spectral results obtained by Guimarães et al., 2014 and assumed stationary during the SWASH simulations.

While the SWAN runs have been performed in a non-stationary mode, the irregular waves are treated as stationary in SWASH. Using the linear wave theory, the velocity at a depth is found by a linear superposition of $N$ harmonic waves whose amplitudes are determined by sampling a variance density spectrum and whose phases are randomly chosen for each realization of the inflow velocity at the boundary, $u_{b}$, given by:

$$
u_{b}(z, t)=\sum_{j=1}^{N} a_{j}\left[\omega_{j} \frac{\cosh k_{j}(z+d)}{\sinh k_{j} h}+\sqrt{\frac{g}{h}}\right] \cos \left(\omega_{j} t-\alpha_{j}\right)-\sqrt{\frac{g}{h}} \zeta,
$$

where $k_{j}$ and $\alpha_{j}$ are the wave number and the random phase, respectively, $\omega_{j}$ is the frequency, and the amplitude of each harmonic is calculated by the wave spectrum $E(\omega)$ as $a_{j}=\sqrt{2 E\left(\omega_{j}\right) \Delta \omega}$, with $\Delta \omega$ is to be the frequency interval.

In the case of inundation or runup, the SWASH model considers a moving shoreline. To calculate the flooded area over the topography, a LIDAR remote sensing system database were employed to supply the bottom condition. The system uses near infrared light to image objects which allows a quick collection of topographical and relief data with a high accuracy. In July 2010 the LIDAR survey was conducted by the LACTEC company. It presented the data on the entire northern coast of Rio Grande do Sul, which is now available from the Rio Grande do Sul Secretariat of the Union Assets (RS-SPU). The post processing was carried out and supplied to the Geological Oceanography Laboratory of Rio Grande Federal University (FURG) by Vianna (2013). Vianna (2013) indicates an altimetric accuracy of $15 \mathrm{~cm}$ to $25 \mathrm{~cm}$. These data were appended in the survey bathymetry lines and interpolated over a SWASH computational grid using the Delaunay triangulation method. The interpolation over the computational grid is shown in Figure 1

One of the SWASH output is the horizontal runup $\left(H_{\text {run }}\right)$, which is a matrix with entries 0 and 1 . These binary values mean land and water points, respectively.

Thus, for a horizontal runup time series analysis it is possible to identify the runup line at each time by 
$\nabla H_{\text {run }} \neq 0$ from which the runup frequency $f_{\text {run }}$, is calculated by

$$
f_{\text {run }}=\frac{\sum_{t_{i}=i}^{n} 2\left|\nabla H_{\text {run }, t}\right|}{n-i}
$$

where $t_{i}$ is the time counter, $i$ is the initial time point in the sum after spin up time and $n$ is the final time point. To calculate the vertical runup excursion we used the landscape model to obtain the runup height. The water level values were subtracted from the runup height to obtain the vertical runup excursion. So the value of $2 \%$ maximum waves runup $\left(R_{2, \text { swash }}\right)$ for the SWASH model were statistically obtained considering a normal distribution for all vertical runup data series at each simulated case.

\subsection{Empirical runup estimation}

In order to evaluate the numerical approach that estimates the runup and inundation in the beach, the numerical results were compared with the empirical model parametrization proposed by Stockdon et al. (2006). The $2 \%$ maximum waves runup is given by the wave induced runup at the storm peak, which is

$$
R_{2}=1.1\left(0.35 \beta_{f}\left(H_{o} L_{o}\right)^{1 / 2}+\frac{\left[H_{o} L_{o}\left(0.563 \beta_{f}^{2}+0.004\right)^{1 / 2}\right]}{2}\right)
$$

where $H_{o}$ is the deep water significant wave height, $L_{o}$ is the deep water wave length given by the the linear dispersion relationship $\left(L_{o}=g T_{p}^{2} / 2 \pi\right)$, and $\beta_{f}$ is the foreshore beach slope derived from the data set.

\section{Validation and events studied}

\subsection{Buoy and model comparison}

Waves measurements at South Atlantic region are extremely rare. For this study, we have carried out a simulation to compare the SWAN model results with one of the few available observational data. Thus, the simulations were compared with the measurements made from November 2006 to May 2007 by the directional buoy moored in $17 \mathrm{~m}$ intermediate water close to Tramandaí city (Strauch et al., 2009). This means that the buoy location over intermediate water depth could measure waves disturbed by the local bathymetry and therefore are not representative of the large-scale wave field. For this analysis, we selected the wave parameters $H_{s}, T_{p}$ and $D$. (Fig. 2 shows the two sets of data at the same period of time).

Overall, the model results were reasonable and satisfactory at intermediate water waves. The coefficients of correlation between the model and the observed data were $0.79-0.85$. The error statistics showed that all 


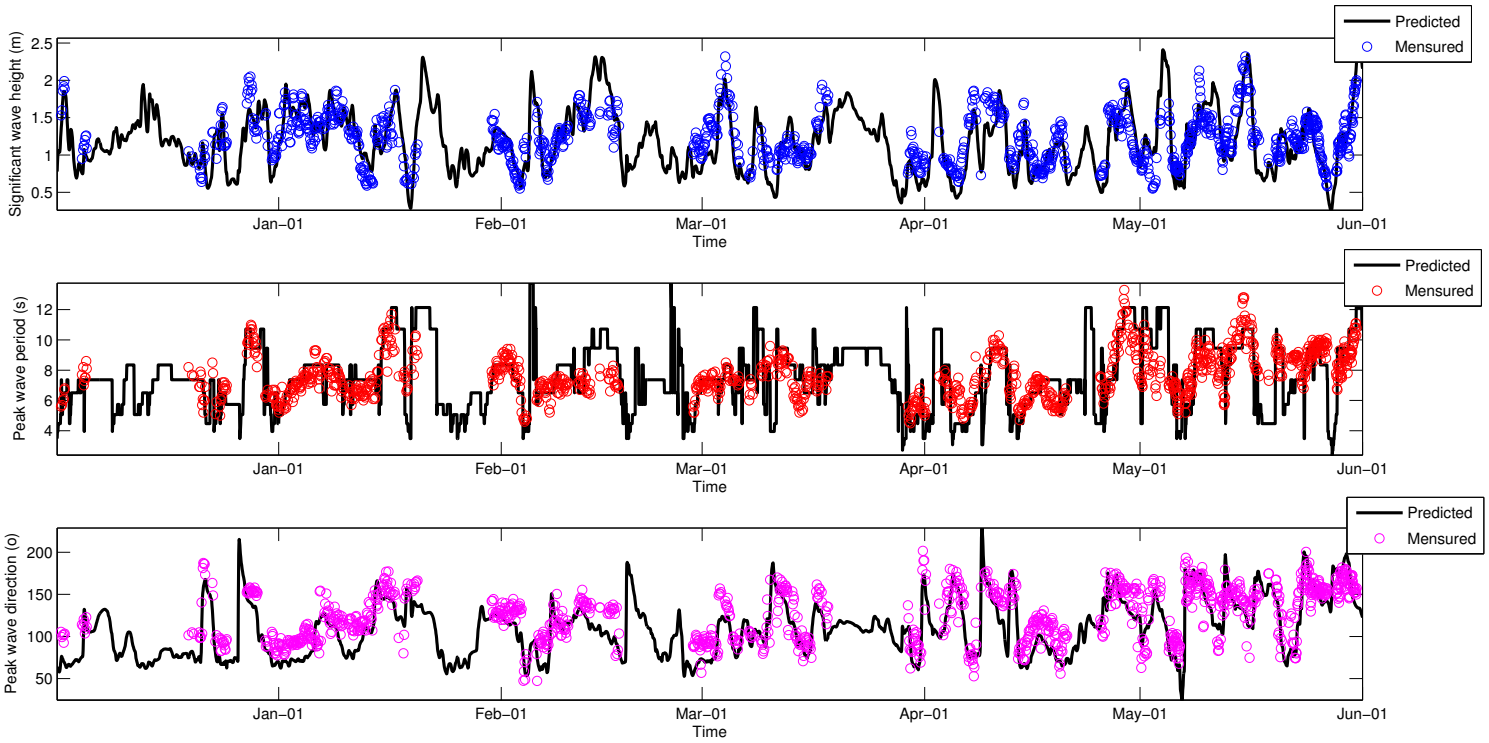

(a)
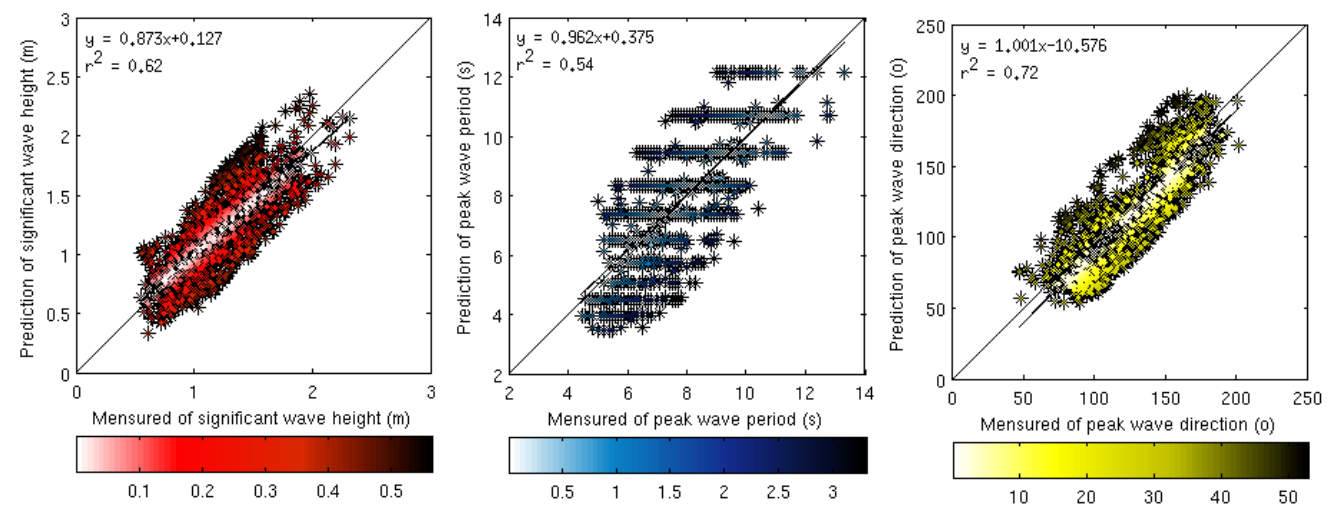

(b)

Figure 2. Validation of the SWAN wave model with the directional buoy data. (a) The SWAN predictions are shown in continuous lines and the buoy data are in circles. (b) Scatter plot of the linear correlation, the colors of the dots represent the distance from the regression line. 
three analyzed wave parameters had a good match with reality in most of the SWAN cases. The model slightly underestimated the significant wave heights. However, the model results follow the buoy variation pattern and move away very fast from the local wave oscillation. Usually the buoy data were overestimated, however in some of the higher events, the model underestimates in the order of $50 \mathrm{~cm}$ than that observed.

\subsection{Runup validation}

In order to validate the wave runup, the experiments were carried out on January 13, 15 and 16, 2014. Measurements of runup at the beach were taken using a Receptor Topcon RTK Hiper Lite in a static mode with the horizontal accuracy of $3 \mathrm{~mm}$. In a stop and a go mode, the receivers were parked on topographical landmarks, collecting data lines simultaneously, over a period of time. With this equipment, two types of wave runup data were measured at the same time: $a$ ) a high frequency runup of each wave spreading over a transversal profile of the beach line; $b$ ) the maximum wave runup along the beach line. In the case $(b)$ the result was directly compared with $f_{r u n}$ as it is shown in figure 3 To make a comparison of runup measurements of type ( $a$ ) with the model, the horizontal distance $d_{h r u n}$, between each wave runup with the minimum swash point observed during the experiment, has been computed. The experiment time corresponding to two measurements of 15 minutes interspersed in 1 hour. The resulting values of the maximum horizontal distance $d_{\text {hrun,max }}$, the mean horizontal distance $\overline{d_{\text {hrun }}}$ and the most frequent distance $d_{\text {hrun,f }}$, are shown in table 2, and are compared with the same parameters obtained from the SWASH model.

The numerical simulations used in the validation process employed the implementations of the models similar to the ones described in the previous subsections. The only difference between the hindcast simulation for extreme events and the SWASH runup validation simulation was the WaveWatchIII global database. While in the extreme events experiment, we used wave boundary conditions and winds surface from NCEP's wave hindcast database, in the SWASH runup validation experiment, we applied the Operational Model Archive and Distribution System (NOMADS, NOAA/NCEP) ${ }^{2}$ for ocean wave predictions database ${ }^{3}$ In this case just the first hours of each WaveWatchIII forecasts runs (00Z, 06Z, 12Z, and 18Z) were used as forcings and boundary conditions for the SWAN model. Three SWASH simulations were carried out for comparison with the runup data collected in the experiment. The table 1 shows the offshore and nearshore significant wave height and the water level used in the SWASH simulation. The results for the SWASH horizontal runup are compared with high frequency measurements over the beach profile described

\footnotetext{
${ }^{2}$ for more information see http://nomads.ncep.noaa.gov/

${ }^{3}$ data source from http://nomad5.ncep.noaa.gov/pub/waves/nww3/
} 
Table 1. The dates and times used in the simulations correspond to the dates and times (in UTC) of the measurements for the runup validation

\begin{tabular}{|cc|cccc|}
\hline \multicolumn{6}{c|}{ Local Conditions } \\
\hline \multicolumn{1}{|c|}{ Date } & $H_{o}[\mathrm{~m}]$ & $H_{s}[\mathrm{~m}]$ & $T_{p}[\mathrm{~s}]$ & $\bar{\zeta}[\mathrm{m}]$ \\
\hline V01 & $13 / 01 / 2014-21 \mathrm{Z}$ & 2.73 & 1.19 & 8.5 & -0.03 \\
V02 & $15 / 01 / 2014-19 \mathrm{Z}$ & 1.35 & 0.76 & 7.0 & -0.08 \\
V03 & $16 / 01 / 2014-10 \mathrm{Z}$ & 1.19 & 0.64 & 6.0 & 0.05 \\
\hline
\end{tabular}

Table 2. Results of the comparison between the SWASH simulations, the field measurements and empirical results for Stockdon et al. 2006 model. The variables maximum horizontal distance $\left(d_{\text {hrun,max }}\right)$, mean horizontal distance $\left(\overline{d_{\text {hrun }}}\right)$ and the most frequent distances $\left(d_{h r u n, f}\right)$ are shown for a beach profile of Tramandaí, located along the line defined by the points $\left(30.004^{o} \mathrm{~S}, 50.132^{\circ} \mathrm{W}\right)$ and $\left(29.981^{\circ} \mathrm{S}\right.$, $50.120^{\circ} \mathrm{W}$ ). The $R_{2, \text { swash }}$ is $2 \%$ maximum waves runup for the SWASH model, considering a normal distribution, $R_{2}$ is the result of $2 \%$ maximum waves runup from Stockdon et al. 2006 model and the $d_{h r u n, R_{2}}$ is the runup projection over $\beta_{f}$ profile. The dates and times used in the simulations correspond to the dates and times (in UTC) of the measurements.

\begin{tabular}{|c|cccc|ccc|cc|}
\hline \multicolumn{1}{c}{ Simulated } & \multicolumn{4}{c}{ Measured } & \multicolumn{2}{c}{ Empirical } \\
\hline & $d_{\text {hrun,max }}[\mathrm{m}]$ & $\overline{d_{\text {hrun }}}[\mathrm{m}]$ & $d_{\text {hrun }, f}[\mathrm{~m}]$ & $R_{2, \text { swash }}[\mathrm{m}]$ & $d_{\text {hrun,max }}[\mathrm{m}]$ & $\overline{d_{\text {hrun }}}[\mathrm{m}]$ & $d_{\text {hrun }, f}[\mathrm{~m}]$ & $R_{2}[\mathrm{~m}]$ & $d_{\text {hrun }, R_{2}}[\mathrm{~m}]$ \\
\hline$V 01$ & 23.62 & 20.52 & {$[18-22]$} & 0.42 & 30.84 & 18.23 & {$[17-20]$} & 0.67 & 67.40 \\
$V 02$ & 12.30 & 9.63 & {$[8-12]$} & 0.30 & 20.52 & 12.31 & {$[11-12]$} & 0.39 & 39.10 \\
$V 03$ & 11.87 & 10.63 & {$[9-12]$} & 0.40 & 18.86 & 8.03 & {$[2-4],[12-15]$} & 0.31 & 31.40 \\
\hline
\end{tabular}

in table 2. This table represents the comparison between the horizontal wave runup distance obtained by the SWASH model (labelled as Simulated), by field experiment (shown as Measured) and by Stockdon $e t$ al. 2006 model (as Empirical). The table (tab. 2) also presents the vertical runup values $R_{2, \text { swash }}$ and $R_{2}$ considering the SWASH results and Stockdon et al. 2006 model.

The SWASH simulation results for $f_{\text {run }}$ (color scale) and the survey campaign data (black dots) obtained on January 15, 2014 at 19Z and on January 16, 2014 at 10Z were plotted over a google maps satellite image and presented in Figure 3

In general, the SWASH model has underestimated the maximum horizontal runup distance. As SWASH reconstructs random waves based on a stationary spectrum condition, it is impossible to compare each wave 

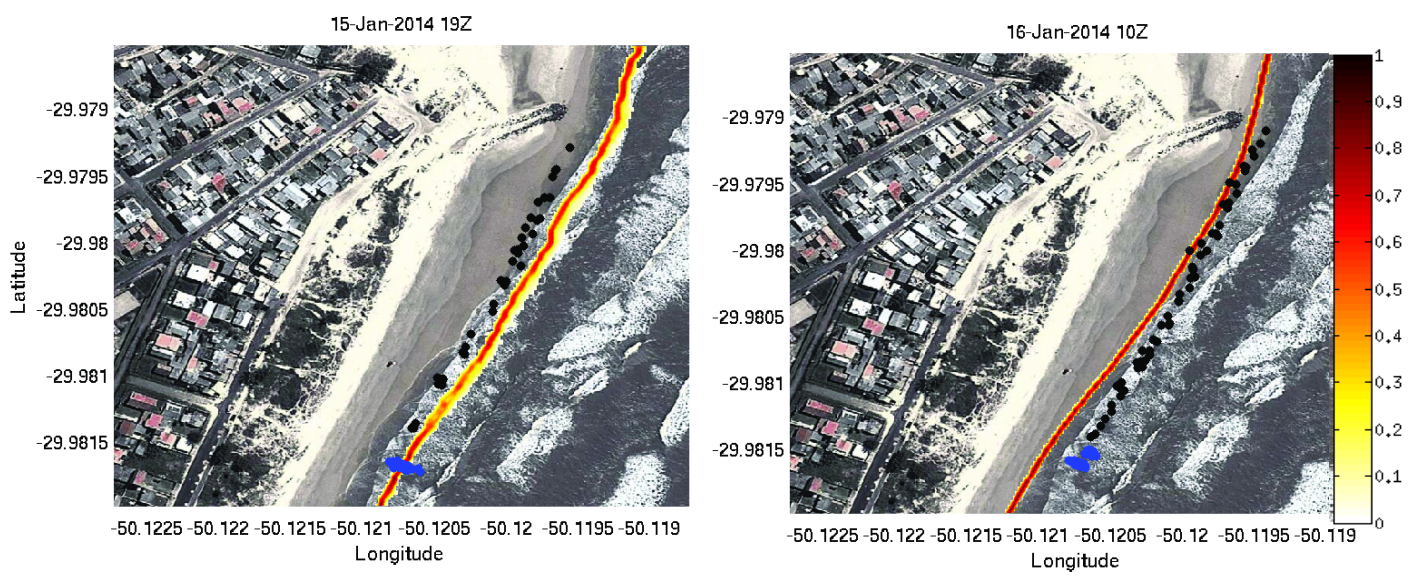

Figure 3. Comparison between the SWASH results $\left(f_{\text {run }}\right)$ (in color scale) and the wave runup observed (in dots).

spreading at the beach with the observed one in the field. However, a comparison is possible for the most frequent wave interval for a runup distance. We found such comparison results are more accurate although an underestimating trend is still present.

Two main reasons are suggested for a SWASH underestimation of the runup distance. One is related to the absence of bathymetry data along the surf zone. A linear interpolation along this zone has been employed and this has reduced the wave energy in the modeled results. Other interpolation schemes have been tested but the linear one was the best option found. Another source of an error for SWASH predictions is due to the changes in the beach morphodynamics stages. The LIDAR survey was carried out in July 2010 (winter) and the runup measurements were taken in January 2014 (Summer). The highly seasonal and interannual wind and a hydrodynamic variability at this region can change the beach morphodynamics pattern introducing errors in the wave runup propagation. Thus, the assumption of a stationary bottom condition is identified as a limitation of this methodology.

The projection of Stockdon et al. 2006 model over the $\beta_{f}$ profile leads to the overestimated $d_{\text {hrun, } R_{2}}$, possibly due the simple definition of $\beta_{f}$ representing the beach profile. This approach does not allow the well representation of slight changes on the beachface morphologies. Moreover, this methodology has been developed to estimate the vertical runup and not the horizontal excursions. Nevertheless, the results for $2 \%$ waves maximum waves runup $R_{2}$ and $R_{2, \text { swash }}$ are close to each other. The small difference between $R_{2}$ and $R_{2, \text { swash }}$ is due to a gentle slope found in this beach that dissipates most of the wave energy in the horizontal runup. In this sense, the SWASH results seem to represent a better solution for runup than the empirical 
method.

\subsection{Storm events}

Six events have been simulated with SWAN. Wave spectra recorded at 41 points along the SWASH boundary (see figure 11) were used in the SWASH simulations of each storm event. Table 3 shows the dates of the events and the main wave parameters computed with the SWAN spectrum and used as stationary boundary conditions for the SWASH simulations. The variables $H_{s}, T_{p}$ and $D_{p}$ presented in table 3 are with respect to the point $29.975^{\circ} \mathrm{S}$ and $50.107^{\circ} \mathrm{W}$, at the east boundary of the SWASH computational grid, while $H_{o}$ represents the significant wave heights for offshore conditions at $30.0^{\circ} \mathrm{S}$ and $49.0^{\circ} \mathrm{W}$.

Table 3. Simulation parameters for the selected extreme wave events. The $\bar{\zeta}$ is the mean water level used in each simulation, $H_{o}$ is the significant waves height at deep water, $H_{s}, T_{p}$ and $D_{p}$ represent respectively the main significant wave height, the peak period and the peak direction extracted from the SWAN spectral waves condition in shallow water during each event at the point $29.975^{\circ} \mathrm{S}$ and $50.107^{\circ}$ W. $R_{2, \text { swash }}$ and $R_{2}$ represent the results of $2 \%$ maximum waves runup for these study cases.

\begin{tabular}{|lc|ccccc|cc|}
\hline Events & Time & $\bar{\zeta}[\mathrm{m}]$ & $H_{o}[\mathrm{~m}]$ & $H_{s}[\mathrm{~m}]$ & $T_{p}[\mathrm{~s}]$ & $D_{p}\left[^{o}\right]$ & $R_{2, \text { swash }}[\mathrm{m}]$ & $R_{2}[\mathrm{~m}]$ \\
\hline E01 & 02-Sep-2002 15:00 & 0.83 & 7.25 & 2.75 & 14 & 135.0 & 1.72 & 1.83 \\
E02 & 27-Jun-2006 03:00 & 0.84 & 8.98 & 2.65 & 14 & 146.6 & 1.31 & 2.04 \\
E03 & 03-Sep-2006 19:00 & 1.38 & 8.42 & 2.23 & 14 & 153.9 & 2.19 & 1.97 \\
$E 04$ & 28-Jul-2007 13:00 & 0.9 & 8.35 & 2.37 & 14 & 136.6 & 1.55 & 1.96 \\
$E 05$ & 03-May-2008 23:00 & 0.76 & 7.99 & 3.72 & 12 & 105.0 & 1.84 & 1.65 \\
$E 06$ & 10-Jun-2008 10:00 & 0.71 & 7.87 & 1.23 & 10 & 44.9 & 1.19 & 1.36 \\
\hline
\end{tabular}

\section{Results and Discussion}

As stated above, six storm wave events were studied in this paper (see Table 3). The SWASH computations for Tramandaí and Imbé beaches resulted in 23 minutes of non-hidrostatic simulations representing the hydrodynamic conditions during each stationary wave event described in Table 3 . The simulations of the events were very computationally demanding. Each simulation of a 28 minutes length took approximately 7 days on 8 cores of a linux workstation with an Intel Core i7 3770k, $3.5 \mathrm{GHz}$ processor using gfortran and mpich2 for the parallel MPI implementation.

For all tested cases, the SWASH results have been compared with the Stockdon et al. 2006 empirical model. The results of this comparison are presented in tables 2 and 3 . Figure 4 shows a scatter plot and the 
linear correction between the $2 \%$ maximum waves runup $R_{2, \text { swash }}$ calculated by the SWASH model and $R_{2}$ from the empirical model. In general, there is a good correlation between the numerical and empirical mod-

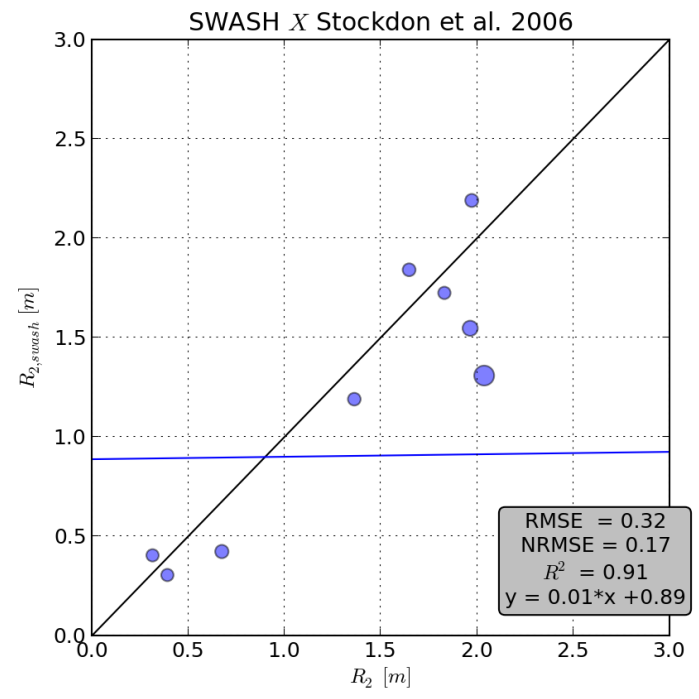

Figure 4. Linear correlation of $2 \%$ maximum waves runup $R_{2, \text { swash }}$ calculated by the SWASH model and $R_{2}$ from Stockdon et al. 2006 model. The correlation box in the figure shows the root mean square error (RMSE), the normalized root mean square error (NRMSE), the linear correlation determination coefficient $R^{2}$ and the linear regression curve.

els, while the empirical model shows a high tendency for an overestimation of the results. The maximum difference between these two methodologies was $72.87 \mathrm{~cm}$ (during the event E02) and the minimum was $8.66 \mathrm{~cm}$ (V02). The mean was $14.02 \mathrm{~cm}$, but this difference can be much bigger in the horizontal direction. Unfortunately, only very few data and field experiments at this region are available which makes impossible to properly evaluate the performance of two models, especially during storm events. However, some concepts can be outlined based on these results. The work by Guimarães et al. 2014 shows that a significant amount of the wave energy during storm events are dissipated in the Rio Grande do Sul shoreface zone. This can explain the large difference between the results of the event E02. The lack of a wave direction and the use of significant wave heights at deep water in the Stockdon et al. 2006 model may limit the representation of the runup developed by the local waves field, during the event $E 02$, under the heterogeneous shoreface with a low slope.

The use of deep water wave conditions, downscaling with the meso-scale wave model to propagate the waves from intermediate and shallow water until the total dissipation of wave energy on the beach, using 
the SWASH model, allows the numerical solution to have many waves and hydrodynamic processes that are not considered in the Stockdon et al. 2006 empirical model. The use of the SWASH model also allows for description of wave propagation and hydrodynamics interactions under different conditions on the beach, such as the presence of walls, side walks, jetties, dunes, sand bars and even urban structures.

While it is expected that the SWASH model represents several different hydrostatic processes in shallow waters, to correctly approach this, a highly accurate landscape model in a high resolution is needed. The use of different numerical models also demands more time for programming, computing and post-processing than the simple application of Stockdon et al. 2006 may require. Thus, the straightforward usage of this empirical model can give a satisfactory general view on a maximum wave runup during most of cases. The large computing time of SWASH can be a disadvantage if the goal is just a study of a critical value for runup, especially compared to Stockdon et al. 2006 where the model has been validated and calibrated for several beaches around the world and an error is just around a few centimeters. On the other hand, if the work intends to evaluate a dynamical procedure with beach interactions, the application of the SWASH model has many advantages.

In all SWASH results obtained, flooding and overtopping scenarios were observed. However during the events $E 01, E 03, E 04$ and $E 05$, these processes were stronger. The event $E 05$ found to be the most extreme case with the waves overtopping the major part of the sidewalk section and flooding all streets behind. In table 3 it is possible to observe that the $E 05$ case is not the most extreme waves event in deep water or has the higher water level, but had the second lowest peak period simulated. Waves with a shorter period take longer to interact with the bottom and then dissipate less energy throughout its propagation and tend to reach the coast with more intensity. The event $E 01$ also presented intense flooding and this suggests that its coast is more vulnerable to waves coming from SE. The events E03 and E04 showed overtopping of the sidewalk walls, though with less intensity. Figure 5 shows the SWASH water levels during the most extreme wave conditions simulated in the event $E 05$ and indicates the zones of significant overtopping and overwashing, denoted and shown there as $Z 1, Z 2$ and $Z 3$. The color scale over the map represents the wet areas due to inundations by the waves and the water level rise. The zones $Z 1$ and $Z 2$ have also been flooded during the events $E 02$ and $E 06$ but the waves and the mean water levels were not high enough to reach the zone Z3. Despite the event $E 06$ has a short wave period, the waves from NE have been dissipating most of their energy at the shoreface and this is the main cause of being the smaller waves case propagated by the SWASH model. For four other cases $(E 01, E 03, E 04, E 05)$, the $Z 3$ region is pointed out as the most vulnerable area to the overtopping process. The zone of the Tramandaí beach is protected by the dunes area and the waves 


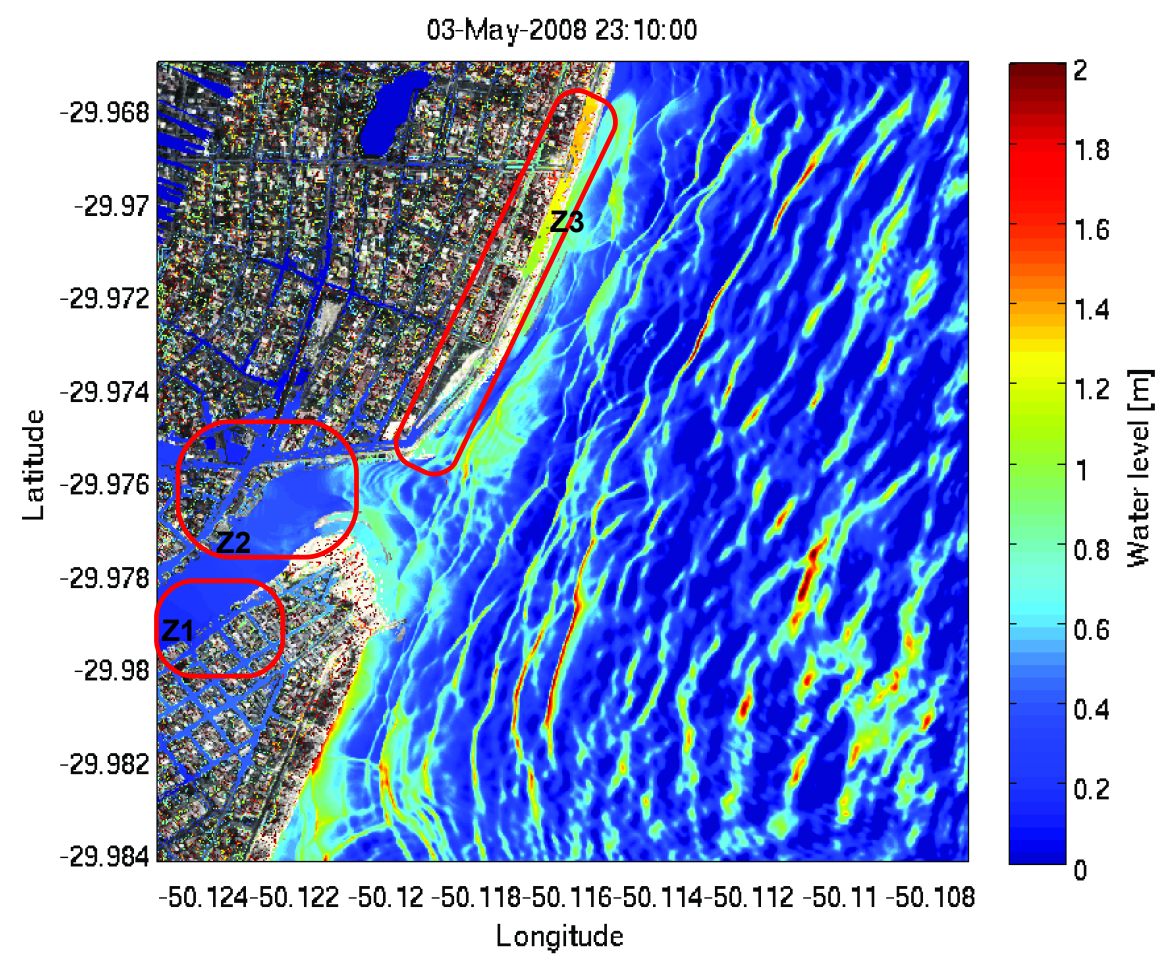

Figure 5. Water level observed on May 03, 2008 23:10:00 on the Tramandaí and Imbé beaches as simulated in the E05 study case. The zones of significant overtopping and overwashing are denoted as $Z 1, Z 2, Z 3$ areas and circled in red.

runup does not create overtopping problems for the urban structures behind the dunes.

Figure 6 shows the frequency of the runup line $f_{\text {run }}$, during the $E 03$ and $E 05$ simulations in the zone Z3 and thus providing the evolution of the SWASH runup in time. The color scale over this map represents the frequency of runup at each wet grid point and the lines around streets and avenues also represent the runup frequency over flooding zones due to waves and the water level increase. The $E 03$ event was selected for this analysis as the one with the largest mean water level, whereas the E05 event demonstrated the highest significant wave height (see Table 3). As can be seen from Figure 6, the waves runup in E05 disperses over the sidewalk, invading and flooding many streets unprotected by foredunes systems. On the other hand, in the event $E 03$, the most of the waves runup have been focused in the sidewalk, overwashing it sometimes in the southern part of the beach.

The result of the continuous process of the waves reaching the sidewalk wall on the Imbé beach during the event $E 03$ was also observed by Jacqueline Estivallet and reported by Aguiar, 2006. Figure 7 shows the 

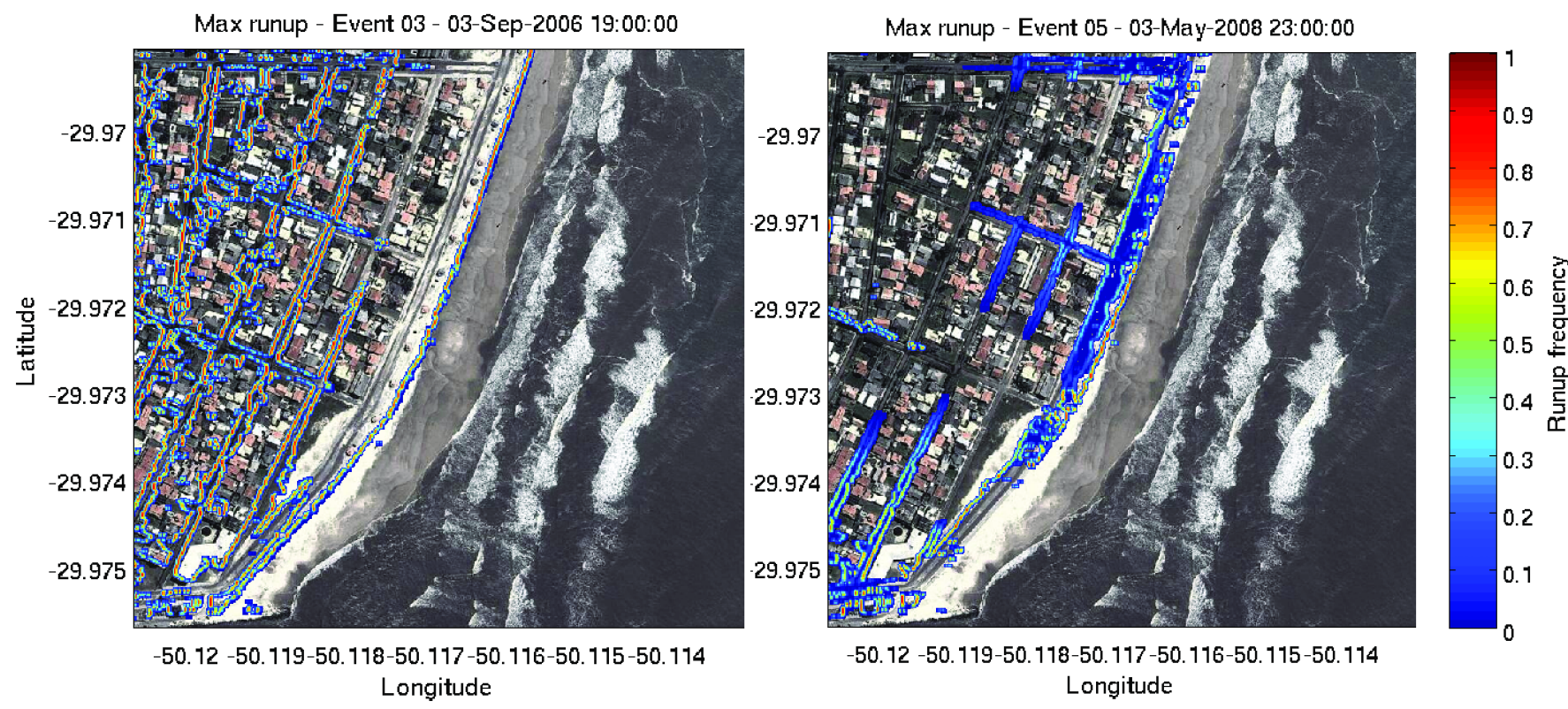

Figure 6. Runup frequency in the zone $Z 3$ for the $E 03$ (left) and $E 05$ (right) experiments extracted from the SWASH simulations.

destruction caused in the Imbé sidewalk in the $Z 3$ zone.

Our simulated results, shown in Figure $6 \mathrm{a}$ are compatible with the pictures in Figures 7 , taken on September 4th, 2006, few hours after the simulated time. We have to stress that the SWASH model demands significant computational resources and thus restricts the storm waves simulations to a short period of analysis. However, despite the relatively short simulated period for each extreme wave event combined with the use of a stationary bottom condition, the results obtained with the SWASH model give a good representation of the phenomena under study.

The simulations with SWASH were able to identify a high variability of water levels in the cities of Tramandaí and Imbé. The value of $1.38 \mathrm{~m}$ for the water level in the event E03 was high enough to flood a big part of the Imbé city and a part of Tramandaí. The LIDAR altimetry shows that some streets in these cities are below this water level. The high inundation zone at Imbé beach can be related to the urban occupation and to the anthropic modification in this region. The urban occupation occurred without an appropriate planning over a depression place which was formerly an estuary zone. Nowadays, this area can be easily flooded during strong rain, spring tides and storm events.

The waves runup, overwashing and overtopping problems in this region have showed to be highly sen- 

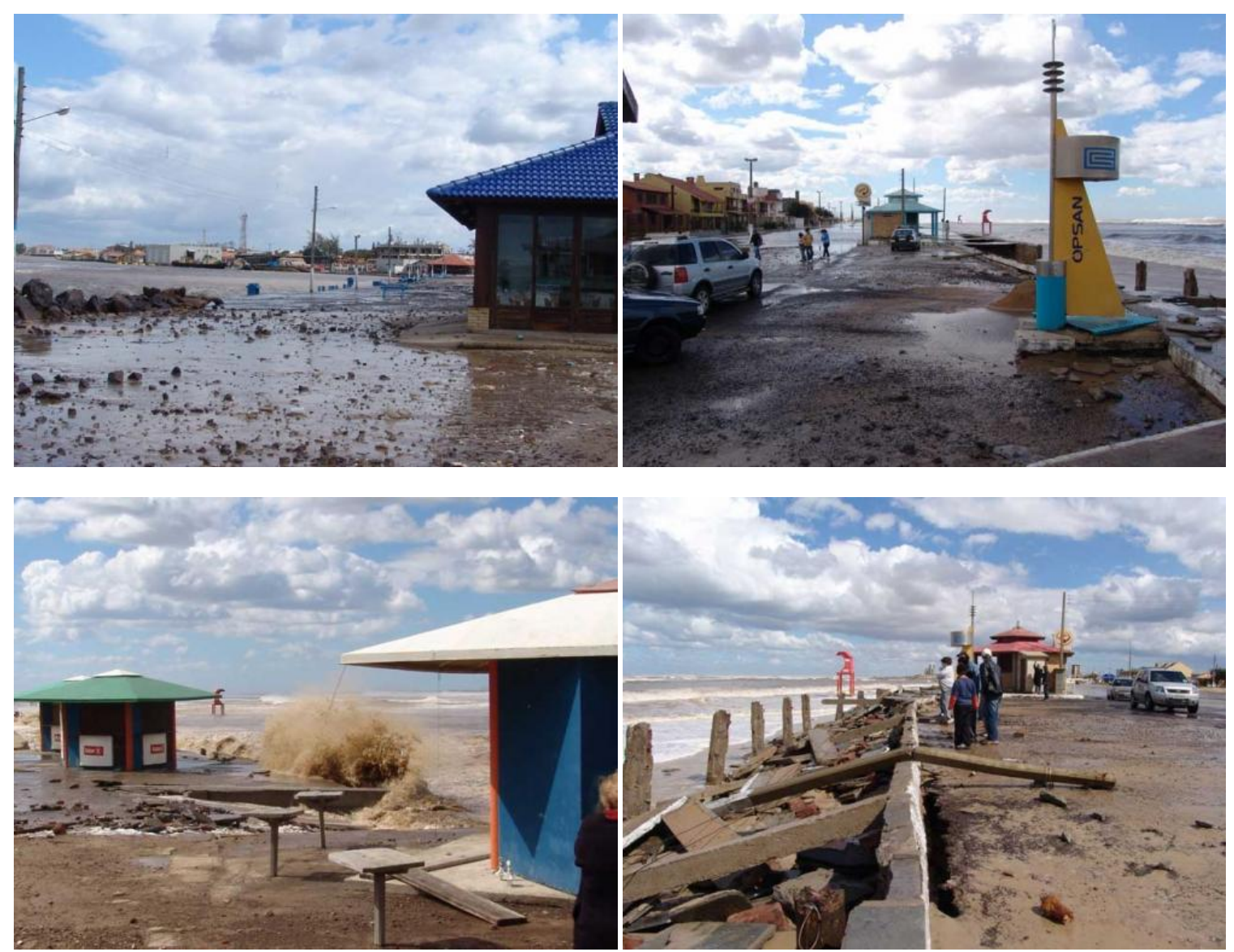

Figure 7. Picture taken on September 04, 2006 during the passage of the event E03 reported by Aguiar 2006 in the meteorological group MetSul.

sitive to the sea water level. As described by Stringari and Marques 2014, the water level in this region, in the synoptic scale, is mainly controlled by the winds pattern. The works of Piola et al., 2005. Braga and Krusche, 2000 and Möller et al., 2008 describe the Rio Grande do Sul coast as highly seasonal and presenting interannual variability of winds field and superficial circulation. Thus, due to the superficial Ekman transport, during the summer month, the NE winds are responsible for setting-down the water level and a consequent decrease of the probability of flooding. During the winter season, the SW winds associated with cold systems, set-up the level in the coast, inducing the wave propagation over the beachshore and increasing the flooding vulnerability. 


\section{Conclusion}

Six storm wave events that affected the coast of Rio Grande do Sul, Brazil, within 2002-2008 were simulated. The zones in the cities of Tramandaí and Imbé that are most vulnerable to overtopping and flooding were identified. The computational approach combined tree different wave models: WaveWatchIII, SWAN and SWASH. This allowed the study of waves at different time and spatial scales, from the formation process at deep water up to the total energy dissipation in the swash zone. The high computational demands of the SWASH model limited the time of analysis to a short period. However, the results are compared well with the real conditions. The comparison of $E 03$ results with the ones observed on the photos also suggests a good representation of waves flooding during extreme events.

In fact, the choices of the appropriate peak spectral waves and maximum water levels propitiated a good representation of the storm waves and the extreme flooding cases during the studied period. To represent well the hydrodynamic interactions with the beach profile, a high resolution of the subaerial surface is essential. The LIDAR scanner provided a surface map with an altimetric accuracy higher than $25 \mathrm{~cm}$. However, the missed bathymetry data along the surf zone and the assumption of a stationary bottom condition during storms are still limitations of this methodology, since during these events a bottom mobility is expected. The time analysis of the SWASH runup showed that the dunes zones on the Tramandaí and the Imbé beaches work as a natural protection structure to the waves impact. No overtopping were observed in the simulations in these zones. On the other hand, the area without dunes protection in the region $Z 3$ at the Imbé beach has been exposed to waves flooding in urban areas in most of the cases analyzed. The zones inside of the estuary $Z 1$ (in Tramandaí) and Z2 (in Imbé) were also identified as critical zones of overwashing, in these two cities.

The SWASH results raised yet another issue. They confirmed that the urban occupation in the former estuary zone in Imbé produced a large susceptibility of flooding risk due to water level variations.

The values of $2 \%$ maximum wave runup calculated from SWASH results and by the Stockdon et al. 2006 empirical model are found to be close. The empirical model usually has overestimated the numerical model and this has been associated with the fact that the empirical model does not take intermediate and shallow water waves into account. However, the low discrepancy between the two results shows that the empirical method may be a good approximation for fast $R_{2}$ calculations, especially if compared with the 7 days needed for calculation of one extreme event by the SWASH model. Despite the subtle variation of the $2 \%$ maximum runup waves, and the faster application, the empirical model does not describe complex hydrodynamic processes and the propagation of waves over the dunes, sidewalks, walls, jetties. However it still gives a good spatial description of the waves runup and flooding zones. 
In summary, this work provided the information on risk conditions during six storm events in the cities of Imbé and Tramandaí, by simulating the highly dynamic zones during extreme hydrodynamic events over natural and urban structures. The methodology proposed and employed in this study can be used as a practical tool for identification of the potential critical flooding zones during storms on the coast of Rio Grande do Sul, thus providing a valuable information for civil protection agencies and coastal authorities.

\section{Acknowledgement}

The first author would like to thank CAPES for the research fellowship and the financial support. Pedro V. Guimarães and Leandro Farina have done a part of the research on this article in the Basque Center for Applied Mathematics (BCAM), as members of the EU project FP7-295217 - HPC-GA. Elena Akhmatskaya would like to thank the Basque Government for the support through the BERC 2014-2017 program and the Spanish Ministry of Economy and Competitiveness MINECO for the support through BCAM Severo Ochoa excellence accreditation SEV-2013-0323. The authors also would like to thank the Brazil's Superintendency of Ports and Waterways for making the water level data available, the Rio Grande do Sul Secretariat of the Union Assets (RS-SPU) and professor Dr. Lauro Calliari for the access to the LIDAR database.

\section{References}

[1] Aguiar, A. A., 2006. Ressaca histórica no litoral gaúcho. URL http: //www . metsul.com/secoes/visualiza.php?cod_subsecao=28\&cod_texto=245

[2] Almeida, L., Vousdoukas, M., Ferreira, O., Rodrigues, B., Matias, a., Mar. 2012. Thresholds for storm impacts on an exposed sandy coastal area in southern Portugal. Geomorphology 143-144, 3-12. URL http://linkinghub.elsevier.com/retrieve/pii/S0169555X11003412

[3] Amante, C., Eakins, B. W., 2009. ETOPO1 1 Arc-Minute Global Relief Model: Procedures, Data Sources and Analysis. NOAA Technical Memorandum NESDIS NGDC-24, 1-19. URL http://www .ngdc.noaa.gov/mgg/global/relief/ETOP01/docs/ETOP01.pdf

[4] Booij, N., Ris, R. C., Holthuijsen, L. H., 1999. A third-generation wave model for coastal regions: 1. Model description and validation. Journal of Geophysical Research 104 (C4), 7649.

URL http://doi.wiley.com/10.1029/98JC02622

[5] Braga, M. F., Krusche, N., 2000. Padrão de ventos em Rio Grande, RS, no período de 1992 a 1995. Atlântica 22, 27-40. 
[6] Callaghan, D. P., Roshanka, R., Andrew, S., 2009. Quantifying the storm erosion Hazard for coastal planning. Coastal Engineering 56 (1), 90-93. URL http://www .sciencedirect.com/science/article/pii/S0378383908001622

[7] Calliari, L. J., Tozzi, H. A. M., Klein, A. H. F., 1998. Beach Morphology and Coastline Erosion Associated with Storm Surges. Anais da Academia Brasileira de Ciências 70, 232-247.

[8] Dietrich, J., Tanaka, S., Westerink, J., Dawson, C., Luettich Jr., R. A., Zijlema, M., Holthuijsen, L., Smith, J., Westerink, L., Westerink, H., 2011. Performance of the Unstructured-Mesh, SWAN+ADCIRC Model in Computing Hurricane Waves and Surge. Journal of Scientific Computing 52 (2), 468-497.

[9] Dillenburg, S. R., Esteves, L. S., Tomazelli, L. J., 2004. A critical evaluation of coastal erosion in Rio Grande do Sul, Southern Brazil. Annals of the Brazilian Academy of Sciences 76 (0001-3765), 611-623.

[10] Fleming, R. J. V., Luettich, R., Fleming, J. G., 2013. Comparative hydrodynamics during events along a barrier island: explanation for overwash. Estuaries and Coasts 36 (2), 334-346.

[11] Guimarães, P. V., Farina, L., Toldo, E., 2014. Analysis of extreme wave events in the southern coast of Brazil. Natural Hazards and Earth System Sciences Discussions 2 (6), 4363-4391.

[12] IBGE, 2010. Census. URL http://www . ibge.gov.br/

[13] Iribarren, C., Nogales, C., 1949. Protection des Ports. In: XVIIth International Navigation Congress. Section II, Communication, pp. $31-80$.

[14] Komen, G. J., Cavaleri, L., Donelan, M., Hasselmann, K., Hasselmann, S., M., J. a. P. A. E., 1994. Dynamics and modelling of ocean waves. Cambridge University Press.

[15] Lima, I. D., Garcia, C. A. E., O., M. O., 1996. Ocean surface processes on the southern Brazilian shelf: characterization and seasonal variability. Continental Shelf Research 16, 1307-1317.

[16] Ma, G., Shi, F., Kirby, J. T., Jan. 2012. Shock-capturing Non-hydrostatic Model for Fully Dispersive Surface Wave Processes. Ocean Modelling 43-44, 22-35.

URL http://linkinghub.elsevier.com/retrieve/pii/S1463500311001892 
[17] Machado, A. A., Calliari, L. J., Melo, E., Klein, A. H. F., 2010. Historical assessment of extreme coastal sea state conditions in southern Brazil and their relation to erosion episodes. Pan-American Journal of Aquatic Sciences 5, 105-114.

[18] Madsen, P. A., Murray, R., Sorensen, O. R., 1991. A new form of the Boussinesq equations with Improved linear dispersion characteristics. Coastal Engineering 15 (4), 371-388. URL http://www.sciencedirect.com/science/article/pii/037838399190017B

[19] Nielsen, P., 2009. Coastal and estuarine processes, 1st Edition. World Scientific Publishing Company, Singapore.

[20] Nwogu, O., 1994. Alternative form of Boussinesq equation for nearshore wave propagation. Journal of Waterway, Port, Coastal, and Ocean Engineering 119 (6), 618-638.

[21] O., M. O., Piola, A. R.and Freitas, A. C., Campos, E. J. D., 2008. The effects of river discharge and seasonal winds on the shelf southeastern South America. Continental Shelf Research 28, 1607-1624.

[22] Parise, C. K., Calliari, L. J., Krusche, N., 2009. Extreme storm surges in the south of brazil: atmospheric conditions and shore erosion. Brazilian Journal of Oceanography 57 (3), 175-188.

[23] Piola, A. R.and Matano, R. P., Palma, E. D., , O., M. O., Campos, E. J. D., 2005. The influence of the Plata River discharge on the western South Atlantic shelf. Geophysical Research 32, 1-4.

[24] Saraiva, J. M. B., Bedran, C., Carneiro, C., 2003. Monitoring of Storm Surges at Cassino Beach. Journal of Coastal Research (0749-0208), 323-331.

[25] Stelling, G., Zijlema, M., 2003. An accurate and efficient finite-difference algorithm for non-hydrostatic free-surface flow with application to wave propagation. International Journal for Numerical Methods in Fluids 43 (1), 1-23.

[26] Stockdon, H. F., Holman, R. A., Howd, P. A., Jr., A. H. S., 2006. Empirical parameterization of setup, swash, and runup. Coastal Engineering 53 (7), 573-588.

URL http://www .sciencedirect.com/science/article/pii/S0378383906000044

[27] Strauch, J. a. C., Cuchiara, D. C., Júnior, E. E. T., Almeida, L. E. S. B., 2009. O padrão das ondas de verão e outono no litoral Sul e Norte do Rio Grande do Sul. RBRH - Revista Brasileira de Recursos Hídricos Volume 14, 29-37. 
[28] Stringari, C. E., Marques, W. C., 2014. Numerical Modeling of Small Scale processes on the Southern Brazilian Inner Shelf . In: Proceedings of the 17th Physics of Estuaries and Coastal Seas (PECS) conference. Porto de Galinhas, p. 4.

[29] Toldo, E., Dillenburg, S., Almeida, L., Tabajara, L., Martins, R., Cunha, L., 1993. Parâmetros morfodinâmicos da Praia de Imbé, RS. Pesquisas em Geociências 20 (1), 27-32.

[30] Toldo, E., Nicolodi, J., Almeida, L., Corrêa, I., Esteves, L., 2006. Coastal dunes and shoreface width as a function of longshore transport . Journal of Coastal Research SI39, 390-394.

[31] Tolman, H., 1991. A third-generation model for wind waves on slowly varying, unsteady and inhomogeneous depths and currents. Journal Physicist of Oceanograph 21, 782-797.

[32] Tolman, H. L., 1997. User manual and system documentation of WAVEWATCH-III version 1.15. NOAA/NWS/NCEP/OMB, United States.

[33] Tolman, H. L., 2009. User manual and system documentation of WAVEWATCH-III. Tech. rep., NOAA / NWS / NCEP / OMB.

[34] Vianna, H. D., 2013. Variabilidade do Sistema Praia-Dunas para o Litoral Norte do Rio Grande do Sul ( Palmares do Sul a Torres -Brasil ) Apoiado em Dados Laser Scanner - Lidar. Ph.D. thesis, Universidade Federal do Rio Grande.

[35] WAMDI, G., 1988. The WAM model - a third generation ocean wave prediction model. J. Phys. Oceanogr. 18, 1775-1810.

[36] Wei, G., Kirby, J. T., Grilli, S. T., Subramanya, R., 1995. A fully nonlinear Boussinesq model for surface waves . Part 1 . Highly nonlinear unsteady waves. Journal of Fluid Mechanics 294, 71-92.

[37] Yamazaki, Y., Kowalik, Z., Cheung, K. F., 2009. Depth-integrated, non-hydrostatic model for wave breaking and run-up. International Journal for Numerical Methods in Fluids 61 (5), 473-497.

[38] Zijlema, M., Stelling, G., Smit, P., Oct. 2011. SWASH: An perational public domain code for simulating wave fields and rapidly varied flows in coastal waters. Coastal Engineering 58 (10), 992-1012. URL http://linkinghub.elsevier.com/retrieve/pii/S0378383911000974 